\title{
Test Study on the Creep Behaviors of Tianjin Clays
}

\author{
Gang $\mathrm{Li}^{1}$, Zhen Yan ${ }^{2}$, Jinli Zhang ${ }^{3 *}$, Jia Liu ${ }^{4}, \mathrm{Yu} \mathrm{Xi}^{1}$ \\ ${ }^{1}$ Shaanxi Key Laboratory of Safety and Durability of Concrete Structures, Xijing University, Xi'an, Shaanxi 710123, China; \\ ${ }^{2}$ Tianjin Research Institute for Water Transport Engineering, Ministry of Transport, Tianjin, 300456, China; \\ ${ }^{3}$ State Key Laboratory of Coastal and Offshore Engineering, Dalian University of Technology, Dalian, Liaoning 116024, China; \\ ${ }^{4}$ School of Geological Engineering and Geomatics, Chang'an University, Xi'an, Shaanxi 710054, China
}

\begin{abstract}
The drained triaxial creep tests were carried out to investigate the relationships between axial strain and time, axial strain and deviatoric stress, and axial strain rate and time for the undisturbed samples of muddy clay and clay in Tianjin. Based on the creep test results, the Singh-Mitchell model was used for creep calculation. The results showed that the muddy clay and clay exhibited typical non-linear creep properties. The axial strain increased with time and then gradually tended to be stable. The strain rate increased as the deviatoric stress increased, and the muddy clay and clay showed the characteristics of attenuation creep under deviatoric stresses. The axial strain of muddy clay was significantly larger than that of clay, and reached the stable state within 3000 minutes. Under low deviatoric stress, the slope of the isochronal curve was smaller; while under high deviatoric stress, the slope of the isochronal curve was larger. The test results were in good agreement with the calculation results, which indicated that the Singh-Mitchell model was suitable for describing the creep behaviors of the undisturbed clays in Tianjin.
\end{abstract}

\section{Introduction}

Clay is widely distributed in coastal areas, with typical characteristics of high water content, large void ratio, high compressibility, low shear strength, low permeability and strong creep. A large number of engineering practice results show that soft clay foundation will produce large post-construction settlement and uneven settlement under long-term load. Therefore, it is necessary to study the creep properties of soft clay systematically. Some scholars have carried out experimental research on creep properties of soft clay. Chen (2011) ${ }^{[1]}$ studied the mechanical characteristics of the sea-land interactive sedimentary soft soil in the Pearl River Delta, and discussed the creep mechanism of the soft soil under drained and undrained conditions. The results showed that the axial deformation under drained condition was mainly caused by the discharge of water in the soil sample, and the creep deformation caused by shear stress was not obvious, the axial deformation under undrained condition depended entirely on the shear strain. Zhou and Chen (2006) ${ }^{[2]}$ adopt triaxial creep test to study the creep properties of undisturbed soft soil in Nansha, Guangzhou. The results showed that the creep properties of soft soil were related to initial consolidation, loading ratio and drained conditions. Under the condition of complete drainage, the consolidation deformation was dominant, while shear creep was dominant under the condition of complete undrained. Kong et al. (2011) ${ }^{[3]}$ discussed the correlation between creep of clay and structure based on the results of the triaxial drainage creep test of structural clay in Zhanjiang. The results showed that the creep behavior of clay was related to its structure, and the creep deformation and creep rate of soil under low deviatoric stress were relatively small, and the volume change with time showed the alternation of shear shrinkage and dilatancy. Yang et al. (2012) ${ }^{[4]}$ studied the creep characteristics of muddy clay in Shanghai by combining digital image measurement method and triaxial creep test. The results showed that the drained conditions will affect the thickness of the water film between the soil particles, and then affect the creep characteristics of the clay. Under undrained condition, the water film thickness between soil particles remains invariant, and the rheological property of soil was relatively large. However, under drained condition, the consolidation of soil leaded to the water film between soil particles becoming thinner, the density and viscosity of soil increased correspondingly, and the rheological property of soil was relatively small, thus producing the Manadei-Cryer effect. Xie et al. (2012) ${ }^{[5]}$ studied the creep characteristics of soft soil in Ningbo, and pointed out that lateral restriction would limit the generation of rheology. The stress-strain isochronal curves under one-dimensional creep tended to stress axis, while the stress-strain isochronal curves under triaxial creep tended to strain axis. Li et al. $(2013)^{[6]}$ studied undrained creep properties of soft soil in Dezhou by triaxial creep test. It was concluded that soft soil had typical non-linear creep properties and was divided into three stages, namely attenuation creep, stable creep and accelerated creep. Creep deformation increased with the increase of stress level. According to Wang et al. (2015) ${ }^{[7]}$, under the

*Corresponding author's email: jlzhang@dlut.edu.cn 
condition of axial loading and lateral load reduction, the drained creep law of saturated silt soil obtained by the two stress paths was basically consistent, that is, creep deformation increases with the increase of stress level.

The distribution of soil has typical regional characteristics. The creep properties of soil are affected by sedimentary history, consolidation state and structure. In this paper, the creep properties of muddy clay and clay in Tianjin were studied by drained triaxial creep test, and the relationship between axial strain and time, axial strain and deviatoric stress, axial strain rate and time was analyzed. Based on the creep test results, the Singh-Mitchell model was used to verify the applicability.

\section{Soils and Testing Methods}

SLB-1 stress or strain controlled triaxial apparatus was used to carry out the drained creep test. The equipment adopts stress or strain control and can carry out UU, CU, $\mathrm{CD}$ test, anisotropic consolidation, isotropic consolidation, back pressure saturation, $K_{0}$ test, stress path test and creep test. The undisturbed soil samples were taken from Beijiang dock of Tianjin port, and the soil depth was between 5-20 m, mainly muddy clay and clay.

The sample diameter and height were $39.1 \mathrm{~mm}$ and $80 \mathrm{~mm}$, respectively. The cell pressure was 50, 100 and $200 \mathrm{kPa}$, which were ascertained by the stress state of the in-situ soil. The test was divided into 4 levels of loading. The loading increment of each level $\left(q_{\mathrm{f}} / 4\right)$ was determined according to the deviator stress $q_{\mathrm{f}}$ when the drained shear test of soil samples reached failure under the same cell pressure. The loading time of each stage was set at 48 hours, and the temperature was controlled at $(20+1)^{\circ} \mathrm{C}$ during the test. The loading scheme is shown in Table 1 .

Table 1. Graded loading scheme

\begin{tabular}{lccccc}
\hline \multirow{2}{*}{ Soil } & & \multicolumn{4}{c}{$q / \mathrm{kPa}$} \\
\cline { 3 - 6 } & $\sigma_{3} / \mathrm{kPa}$ & Level & Level & Level & Level \\
& & 1 & 2 & 3 & 4 \\
\hline \multirow{2}{*}{ Muddy } & 50 & 20 & 40 & 60 & 80 \\
clay & 100 & 25 & 50 & 75 & 100 \\
& 200 & 40 & 80 & 120 & 160 \\
\multirow{4}{*}{ Clay } & 50 & 24 & 48 & 72 & 96 \\
& 100 & 30 & 60 & 90 & 120 \\
& 200 & 50 & 100 & 150 & 200 \\
\hline
\end{tabular}

\section{Test Results and Analysis}

\subsection{Relationships between the axial strain and time}

In order to analyze the drained creep properties of undisturbed muddy clay and clay in Tianjin, the Chen's method was used to process the test data. Taking the test results under the cell pressure of $50 \mathrm{kPa}$ as an example, the axial strain time-history curves of muddy clay and clay are shown in Figure 1. As can be seen from the figure, the creep curve shows typical nonlinear characteristics. At the initial stage of deviatoric stress, the axial strain increases significantly with the increase of time, and then gradually tends to be stable. The axial strain increases with the increase of deviating stress, showing attenuation creep properties. Under the same cell pressure, the axial strain of the muddy clay is significantly larger than that of the clay, which indicates that the shear strength of the muddy clay is lower and the creep property is stronger. On the whole, the muddy clay and clay in Tianjin showed typical non-linear creep properties, and reach stable state within 3000 minutes under deviatoric stress.

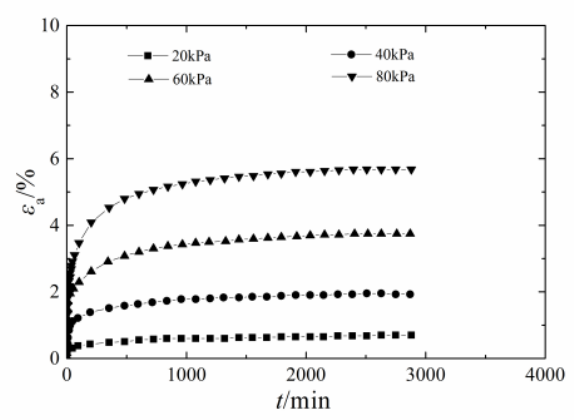

(a) muddy clay

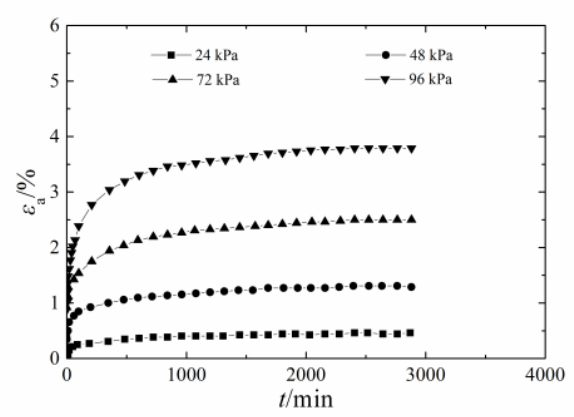

(b) clay

Figure 1. Axial strain versus time under the cell pressure of 50 $\mathrm{kPa}$

\subsection{Relationships between the axial strain and deviator stress}

In order to analyze the stress-strain relationship of muddy clay and clay, the isochronal curves of stress-strain under the cell pressure of $50 \mathrm{kPa}$ is shown in Figure 2. It can be seen that, the isochronal curves of different soils show typical non-linear characteristics. Under the low deviating stress, the slope of the isochronal curve is smaller; while under the high deviating stress, the slope of the isochronal curve is larger. Comparing the stress-strain curves of muddy clay and clay, it can be seen that the distribution of isochronal curves is basically the same. With the increase of isochronal curve time, the slope of the curve increases gradually, while the difference between adjacent curves decreases gradually, which indicates that the creep of soil tends to be stable with the increase of time. 


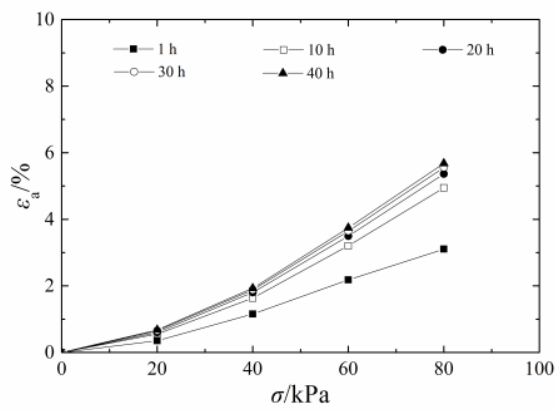

(a) muddy clay

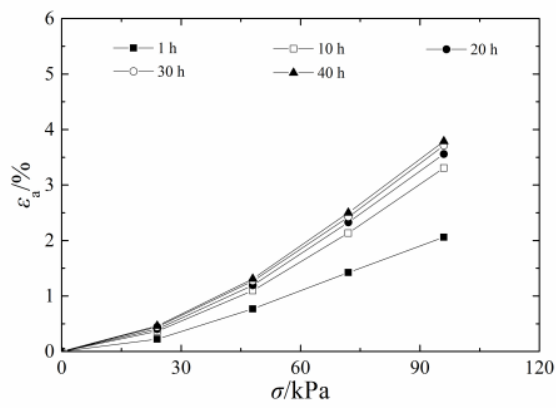

(b) clay

Figure 2. Axial strain versus stress under the cell pressure of 50 $\mathrm{kPa}$

\subsection{Relationships between axial strain rates and time}

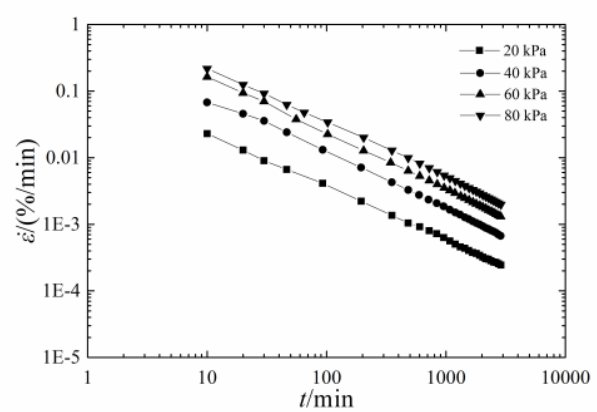

(a) muddy clay

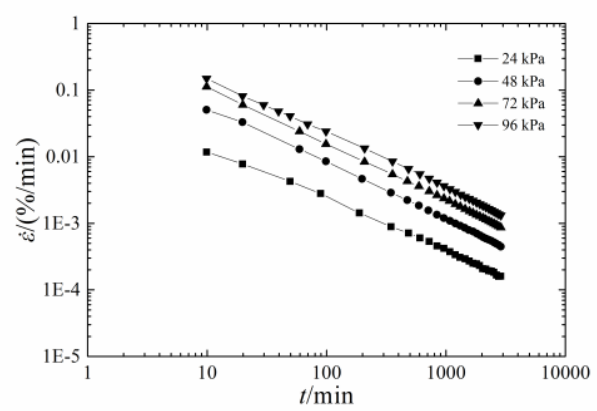

(b) clay

Figure 3. Axial strain rate versus time under the cell pressure of $50 \mathrm{kPa}$

Figure 3 shows the double logarithmic curve between axial strain rate and time under cell pressure of $50 \mathrm{kPa}$. It can be seen that the rule of creep rate curve is basically the same under different deviatoric stress, and the creep rate decreases linearly with the time increased. The strain rate of soil increases with the increase of deviatoric stress, and the slope of creep curve is basically the same under different deviatoric stress, which indicates that the deviatoric stress has little effect on the slope of creep curve. On the whole, the muddy clay and clay exhibited attenuation creep behaviors under deviatoric stress, which is consistent with the above analysis.

\section{Creep Model}

\subsection{Singh-Mitchell mode ${ }^{[8-10]}$}

In 1968, Singh A and Mitchell J K summarized the experimental data of single-stage constant stress loading, drained and undrained triaxial compression, and proposed a widely used creep model. The Singh-Mitchell creep model can be expressed as:

$$
\dot{\varepsilon}=A_{r} e^{\alpha D_{r}}\left(t_{r} / t\right)^{m}
$$

where $\dot{\varepsilon}$ is the axial strain rate; $t$ is the loading time; $D_{\mathrm{r}}=\left(\sigma_{1}-\sigma_{3}\right) /\left(\sigma_{1}-\sigma_{3}\right)_{\mathrm{f}}$ is the deviatoric stress level; $A_{\mathrm{r}}$ is the strain rate at the unit reference time when the deviatoric stress level is zero; $-m$ is the slope of straight line in $\ln \varepsilon-\ln t ; \alpha$ is the slope of the linear segment in the relationship between the logarithm of strain rate and shear stress. The Singh-Mitchell model involves three parameters, namely $\alpha, A_{\mathrm{r}}$ and $m$, respectively.

When $m \neq 1$ and strain is ignored, the formula (1) can be derivated as

$$
\varepsilon=B e^{\beta D_{r}}\left(t / t_{r}\right)^{\lambda}
$$

Where $B=A_{\mathrm{r}} t_{\mathrm{r}} /(1-m) ; \quad \beta=\alpha ; \quad \lambda=1-m$. The three parameters that the model needs to determine are $B, \beta$ and $\lambda$.

When $t=t_{\mathrm{r}}$, formula (2) can be written as:

$$
\begin{gathered}
\varepsilon_{r}=B e^{\beta D_{r}} \\
\ln \varepsilon_{r}=\beta D_{r}+\ln B
\end{gathered}
$$

Thus, according to equations (3) and (4), $\beta$ and B can be obtained directly from the slope and intercept in the relation curve of $\ln \varepsilon_{\mathrm{r}}-D_{\mathrm{r}}$ at the time of $t_{\mathrm{r}}=1 \mathrm{~d}$ (or $1 \mathrm{~h}$ ). $\lambda$ is determined by the slope on the curve of $\ln \varepsilon-\ln t$.

\subsection{Model parameters}

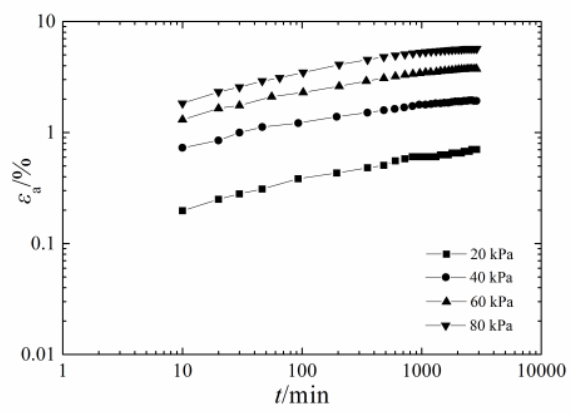

(a) $\ln \varepsilon-\ln t$ 


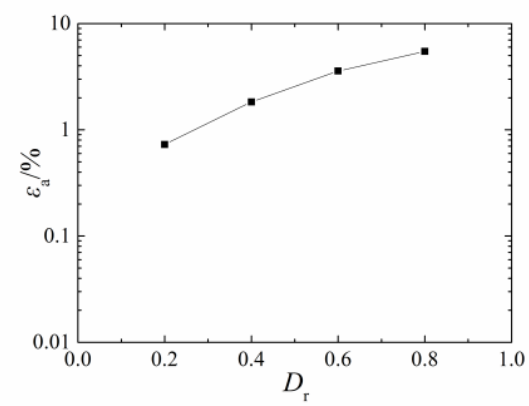

(b) $\ln \varepsilon_{\mathrm{r}}-D_{\mathrm{r}}$

Figure 4. Fitting curve of muddy clay under cell pressure of 50 $\mathrm{kPa}$

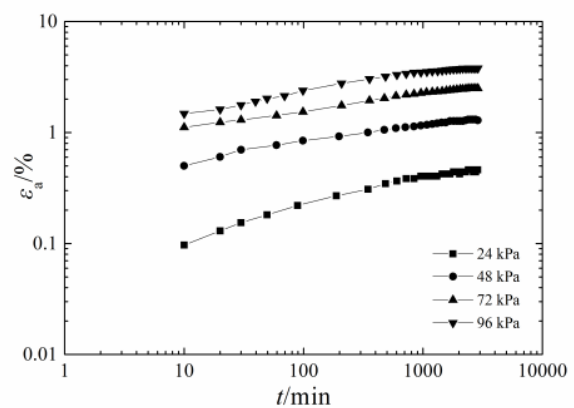

(a) $\ln \varepsilon-\ln t$

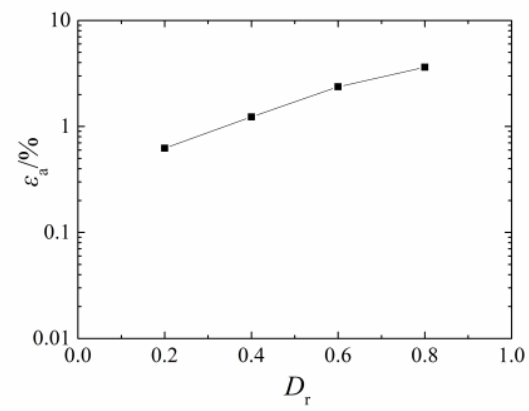

(b) $\ln \varepsilon \mathrm{r}-D_{\mathrm{r}}$

Figure 5. Fitting curve of clay under cell pressure of $50 \mathrm{kPa}$

In order to obtain the parameters of Singh-Mitchell model, the test results of muddy clay and clay were taken as an example under $50 \mathrm{kPa}$ cell pressure, the reference time was set for $1 \mathrm{~d}$. The fitting results are shown in Figure 4 and Figure 5. It can be seen that under the double logarithmic coordinates, the linear relationship between $\varepsilon_{\mathrm{a}}$ and $t$ under various deviating stresses is basically present, and the correlation coefficient is greater than 0.91 . In single logarithmic coordinates, the relation between $\varepsilon_{\mathrm{a}}$ and $D_{\mathrm{r}}$ is also linear with the coefficient of correlation greater than 0.85 . The model parameters obtained by fitting analysis are shown in Table 2.
Table 2. Singh-Mitchell model parameters

\begin{tabular}{|c|c|c|c|c|c|c|c|}
\hline \multirow[b]{2}{*}{ Soil } & \multirow[b]{2}{*}{$B$} & \multirow[b]{2}{*}{$\beta$} & \multicolumn{5}{|c|}{$\lambda$} \\
\hline & & & $\begin{array}{c}\text { level } \\
1\end{array}$ & $\begin{array}{c}\text { level } \\
2\end{array}$ & $\begin{array}{c}\text { level } \\
3\end{array}$ & $\begin{array}{c}\text { level } \\
4\end{array}$ & $\begin{array}{c}\text { avera } \\
\text { ge }\end{array}$ \\
\hline $\begin{array}{l}\text { Mud } \\
\text { dy } \\
\text { clay }\end{array}$ & $\begin{array}{c}0.369 \\
811\end{array}$ & $\begin{array}{c}3.743 \\
307\end{array}$ & $\begin{array}{c}0.287 \\
623\end{array}$ & $\begin{array}{c}0.167 \\
276\end{array}$ & $\begin{array}{c}0.170 \\
048\end{array}$ & $\begin{array}{c}0.169 \\
170\end{array}$ & $\begin{array}{c}0.198 \\
529\end{array}$ \\
\hline Clay & $\begin{array}{c}0.244 \\
418\end{array}$ & $\begin{array}{c}3.634 \\
462\end{array}$ & $\begin{array}{c}0.262 \\
375\end{array}$ & $\begin{array}{c}0.171 \\
150\end{array}$ & $\begin{array}{c}0.173 \\
611\end{array}$ & $\begin{array}{c}0.171 \\
988\end{array}$ & $\begin{array}{c}0.194 \\
781\end{array}$ \\
\hline
\end{tabular}

\subsection{Model calculation}

The model parameters in Table 2 were substituted into the Singh-Mitchell model, and the comparison between the calculation and test results were shown in Figure 6. It can be seen that the test results coincide with the calculation results of the muddy clay and clay under the low deviatoric stress. In the case of high deviatoric stress, the difference between the test results and the calculation results is large. With the increase of time, the match between the two results is getting better and better. Overall, the test results are consistent with the calculation results, which verifying the reliability of the Singh-Mitchell model. In the meantime, it is shown that the Singh-Mitchell model is suitable for describing the creep behavior of undisturbed muddy clay and clay in Tianjin.

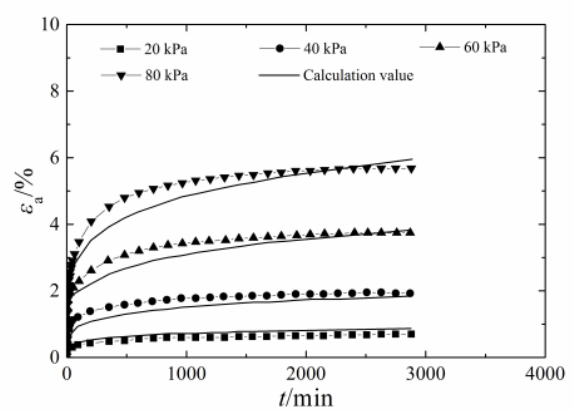

(a) muddy clay

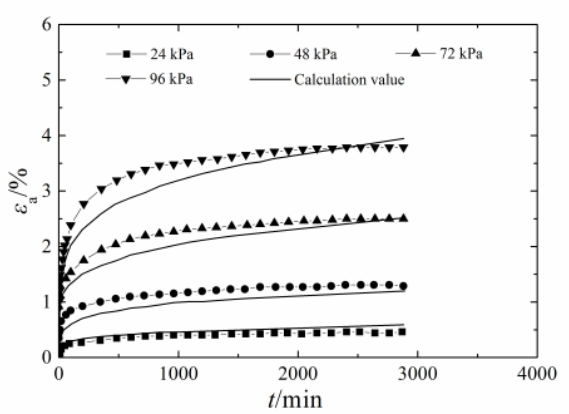

(b) clay

Figure 6. Results comparison between test and calculation under the cell pressure of $50 \mathrm{kPa}$

\section{Conclusions}

(1) The muddy clay and clay in Tianjin exhibited typical non-linear creep properties, and the axial strain increased significantly with the increase of time, then gradually tended to be stable. Among them, the axial strain of 
muddy clay was significantly larger than that of clay, and it reached the stable state within 3000 minutes under deviatoric stress.

(2) The slope of isochronal curve was smaller under low deviatoric stress, while the slope of isochronal curve was larger under high deviatoric stress. The strain rate increased with the increase of deviatoric stress, and the muddy clay and clay showed the characteristics of attenuation creep.

(3) The Singh-Mitchell model was used to calculate the creep test results, and the calculated results were consistent with the test results, which indicates that the Singh-Mitchell model is suitable for describing the creep behaviors of undisturbed muddy clay and clay in Tianjin.

\section{Acknowledgments}

This study was supported by the Special Fund for Scientific Research by Xijing University (XJ18T01), Special Fund for Scientific Research by Shaanxi Provincial Education Department (18JK1199), and the Fundamental Research Funds for the Central Research Institutes (TKS170102 and TKS170108).

\section{References}

1. Chen, X. P. (2011) Consolidation effect of soft soil in interactive marine and terrestrial deposit. J. Chinese Journal of Geotechnical Engineering, 33(4): 520-528.

2. Zhou, Q. J., Chen, X. P. (2006) Experimental study on creep characteristics of soft soils. J. Chinese Journal of Geotechnical Engineering, 28(5): 626-630.

3. Kong, L. W., Zhang, X. W., Guo, A. G., et al. (2011) Creep behavior of Zhanjiang strong structured clay by drained triaxial test. J. Chinese Journal of Rock Mechanics and Engineering, 30(2): 365-372.

4. Yang, C., Wang, R., Meng, Q. S. (2012) Study of soft soil triaxial shear creep test and model analysis. J. Rock and Soil Mechanics, 33 (S1): 105-111.

5. Xie, X. Y., Li, J. Z., Wang, W. J., et al. (2012) Rheological test and empirical model of Ningbo soft soil. J. Journal of Zhejiang University (Engineering Science), 46(1): 64-71.

6. Li, Z. L., Xu, Z. L., Yang, A. W., et al. (2013) Laboratory study on creep behavior and constitutive model of soft soil in Dezhou. J. Journal of Engineering Geology, 21(6): 967-972.

7. Wang, Y. F., Cai, Z. Y., Zhou, Z. G., et al. (2015) Creep characteristics of an oozy soil under drained k0 consolidation. J. Rock and Soil Mechanics, 36(8): 2243-2248.

8. Singh, A., Mitchell, J. K. (1968) General stress-strain-time function for soils. J. Journal of the Soil Mechanics and Foundation Divisions, 94(1): 21-46.

9. Sun, M. Q., Wang, Q., Niu, C. C., et al. (2016) Research on the one-dimensional rheological consolidation theory that considers secondary consolidation effect. J. Journal of Computational and Theoretical Nanoscience, 13(2): 1136-1146.

10. Brandes, H. G., Sadd, M. H., Silva, A. J. (1996) Finite element modelling of a deep sea clay in long-term laboratory creep tests. J. International Journal for numerical and Analytical Methods in Geomechanics, 20(12): 887-905. 